\title{
MELHORAMENTO DO TRIGO: XXIV. AVALIAÇÃO DE NOVOS GENÓTIPOS NO ESTADO DE SÃO PAULO ( $\left.{ }^{1}\right)$
}

\author{
CARLOS EDUARDO DE OLIVEIRA CAMARGO $(2,5)$, JOÃO CARLOS FELÍCIO $\left({ }^{2,5}\right)$, \\ ANTONIO WILSON PENTEADO FERREIRA FILHO $(2,5)$, JOSÉ GUILHERME \\ DE FREITAS $\left({ }^{2,5}\right)$, RICARDO AUGUSTO DIAS KANTHACK $\left({ }^{3}\right)$ e BENEDITO \\ DE CAMARGO BARROS $\left({ }^{4,5}\right)$
}

\begin{abstract}
RESUMO
Compararam-se vinte e três linhagens de diversas origens e dois cultivares de trigo em ensaios tanto em condição de irrigação por aspersão como de sequeiro, analisando-se a produçăo de grãos, outros componentes da produção e resistência às doenças. Em casa de vegetação, estudou-se a resistência às misturas de raças prevalecentes dos agentes causais da ferrugem-do-colmo e da-folha e, em condições de laboratório, a tolerância ao alumínio, em soluções nutritivas. As linhagens IAC-243, IAC-187 e IAC-188, de porte baixo, resistentes ao acamamento e de ciclo médio, $\theta$ a linhagem IAC-190, de porte médio, salientaram-se quanto à produção de grãos em condições de irrigação por aspersão. Em sequeiro, destacaram-se quanto à produtividade as linhagens IAC-188 e IAC-193, de porte baixo, resistentes ao acamamento $\theta$ de ciclo precoce. A linhagem 17 mostrou resistência às três misturas de raças prevalecentes do agente causal da ferrugem-da-folha em estádio de plântula, imunidade a essa ferrugem em condiçōes de campo (planta adulta), resistência às duas misturas de raças de ferrugem-do-colmo, moderada resistência ao oídio e menor grau de área infectada pelos patógenos causadores de manchas foliares. 0 cultivar Alondra-S-46 mostrou ser fonte genética do caráter espiga comprida; a linhagem IAC-182, de maior número de espiguetas por espiga; 'Anahuac', de maior número de grãos por espiga e por espigueta e as linhagens IAC-188 e 17, de grãos mais pesados. As linhagens 2, IAC-182, IAC-243, 7, IAC-186, IAC-187 e IAC-193 foram as mais tolerantes à toxicidade de alumínio.
\end{abstract}

Termos de indexação: trigo; componentes da produção; resistência a doenças; tolerância ao alumínio.

(') Com verba suplementar do Acordo do Trigo entre as Cooperativas de Produtores Rurais do Vale do Paranapanema e a Secretaria de Agricultura e Abastecimento, através do Instituto Agronômico. Recebido para publicação em 5 de setembro de 1990 e aceito em 30 de setembro de 1991.

(2) Seção de Arroz e Cereais de Inverno, Instituto Agronômico (IAC), Caixa Postal 28, 13001 Campinas, SP.

(3) Estação Experimental de Assis, IAC.

(4) Seção de Doenças das Plantas Alimentícias Básicas e Olerícolas, Instituto Biológico (IB), 13093 Campinas, SP.

(5) Com bolsa de pesquisa do CNPq. 


\title{
ABSTRACT \\ WHEAT BREEDING: XXIV. EVALUATION OF NEW GENOTYPES FOR THE STATE OF SÃO PAULO, BRAZIL
}

\begin{abstract}
Seventeen inbred lines selected from hybrid populations introduced from Oregon State University, U.S.A., two lines from Chile, four lines from Móxico and two wheat cultivars (Anahuac and Alondra-S-46) were evaluated in three trials carried out at Campinas (1984, 1986 and 1987) under sprinkler irrigation. Two trials were carried out at different locations of the Paranapanema Valley (1985 and 1986), in upland conditions, taking into account the grain yield, yield components and disease resistance. Under greenhouse conditions the studies aimed to assess the response of the genotypes for the two race mixtures of stem rust and for three race mixtures of leaf rust. Under laboratory conditions, the germoplasms were evaluated to $A$ toxicity using nutrient solutions. The lines 5 (Sonora 64/S 52/4/Tezanos Pintos Precoz//IRN46/ $/$ CIANO/3/Chris) $=$ IAC-243, 12 (Bezostaja/Sava//Anza) $=$ IAC-187 and 13 (II 54$-66 /$ Collafen//Alondra $)=\mid A C-188$ presented short stature, lodging resistance, medium cycle from emergence to flowering. The line 16 (Lilifen *2// *2 Dijon/8316/3/Pavon) = IAC-190 showed medium stature, and good grain yield under irrigated conditions. The line 22 (Trush "S") = IAC-193 showed short stature, earliness, and lodging resistance. The lines 22 and 13 were the most productive in upland conditions. The line 17 (Rannjaja/Leonardo/3/4/ Tezanos Pintos Precoz//IRN 46/CIANO/3/Chris) showed resistance to three race mixtures of leaf rust (Puccinia recondita) under greenhouse, however, under field conditions this line revealed immunity to this patogen; resistance to two race mixtures of stem rust (P. graminis $f$. sp. tritici) was noted. Moderate resistance to powdery mildew in adult stage of the plants was observed as well as a relatively low amount of leaf spots, under field conditions. The cultivar Alondra-S-46 showed to be a good genetic source for long head, the line 3 (Frontana/Cheyenne//llle de France/3/Chiroca) $=$ IAC-182 revealed good for number of spikelets per head. The cultivar Anahuac for large number of grains per head and per spikelet. The lines 13 and 17 were considered good for heavy grains. The lines 2 (Lilifen* 2//*2 Dijon/8316/3/Pavon), 3, 5, 7 (Bragado/Pavon), 10 (Cappelle Desprez/2* Pullman Selection 101//Pavon) $=\mid A C-186,12$ and 22 were the most tolerant to $A^{3+}$ toxicity.
\end{abstract}

Index terms: wheat; yield components; disease resistance; aluminum tolerance.

\section{INTRODUÇÃO}

Cultivares de trigo de origem mexicana do tipo de primavera estão sendo recomendados aos agricultores paulistas, desde 1970 (CAMARGO, 1972; CAMARGO et al., 1974, 1988, FELÍCIO et al., 1976) por seu alto potencial de rendimento de grãos, aliado ao porte baixo e resistência ao acamamento, porém somente para solos corrigidos, devido à elevada sensibilidade ao $\mathrm{A}^{3+}$ presente no solo. Mesmo nos corrigidos, com porcentagem de saturação por bases (V\%) igual ou superior a 60 , em anos secos, quando há necessidade de o sistema radicular das plantas de trigo aprofundar no perfil do solo em busca de água, os cultivares mexicanos não têm mostrado bom desempenho, pela restrição do crescimento de suas ralizes no subsolo com a presença de $\mathrm{Al}^{3+}$ (CAMARGO \& OLIVEIRA, 1981, e CAMARGO \& FELICIO, 1986). 
Apesar do lançamento de vários cultivares mexicanos para o Estado de São Paulo, esses genótipos, em geral, têm apresentado baixa estabilidade de rendimento de grãos, através dos anos, ao contrário da mostrada pelos cultivares $\mathrm{BH}-1146$ e IAC-18 (FERREIRA FILHO et al., 1990). Além disso, sua resistência aos agentes causais da ferrugem-do-colmo e da-folha, bem como da brusone, tem sido quebrada com poucos anos de cultivo comercial.

Tendo em vista a pequena variabilidade genética entre os germoplasmas de trigo de primavera utilizados nos programas de melhoramento, em diferentes instituições de pesquisa, a Universidade Estadual de Oregon (EUA), em convênio com o Centro Internacional de Melhoramento de Milho e Trigo (CIMMYT), México, e outras instituições, vêm coordenando um trabalho visando aumentar a variabilidade genética através de cruzamentos entre germoplasmas de trigo do tipo de inverno, que requerem vernalização, e de primavera. As sementes híbridas, em geração $F_{2}$, são distribuidas a dezenas de países interessados em aproveitar 0 potencial genético existente nesse material visando a aumentar a produtividade dos trigos de inverno ou de primavera, conforme o caso.

O presente trabalho teve por objetivo avaliar, em condição de sequeiro e de irrigação por aspersão, o comportamento de linhagens de trigo provenientes de cruzamentos entre genótipos mexicanos do tipo de primavera e aquelas originárias de cruzamentos entre genótipos do tipo primavera e de inverno, em comparação com os cultivares Anahuac e Alondra-S-46, de origem mexicana, atualmente recomendados para o Estado de São Paulo.

\section{MATERIAL E MÉTODOS}

Incluiram-se nos ensaios vinte e três linhagens e dois cultivares controles cuja origem e genealogia se encontram a seguir:

As linhagens 1 a 17 foram selecionadas no Instituto Agronômico a partir de populações híbridas entre trigos de inverno e de primavera, introduzidos da Universidade Estadual de Oregon em 1979.

Linhagens Genealogia

1 ..... Pitic-62/Mazoe//CIANO/3/Lilifen/4/Sol.

2 ..... Lilifen* 2//*2 Dijon/8316/3/Pavon.

3 .... Frontana/Cheyenne//lle de France/3/Chiroca - IAC-182.

4 ..... Bragado/Pavon = IAC-183.

5 .... Sonora64/S52/4/Tezanos Pintos Precoz//IRN 46/CIANO/3/Chris = IAC-243.

6 ..... Bragado/Pavon = IAC-184.

7 ..... Bragado/Pavon.

8 .... Bragado/Pavon. 
9 ..... Bragado/Pavon $=$ IAC-185.

10 ..... Cappelle Desprez/2* Pullman Selection 101//Pavon = IAC-186.

11 ..... Pichon//Kotare 4 Aegilops sp./Narino 59/3/Castano Colorado.

12 ..... Bezostaja/Sava//Anza $=$ IAC-187.

13 ..... II 54-66/Collafen//Alondra $=$ IAC-188.

14 ..... Bezostaja 1/Pichon/4/Chris/S 948//4* Chris/3/ II 8156.

15 .... Lilifen *2//*2 Dijon/8316/3/ Pavon $=$ IAC-189.

16 ..... Lilifen *2//* 2 Dijon/8316/3/ Pavon $=$ IAC-190.

17 ..... Rannjaja/Leonardo 13/4/Tezanos Pintos Precoz//IRN 46/CIANO/3/Chris.

As linhagens 18 e 19 foram introduzidas através do ensaio denominado "Lineas Avanzadas del Cono Sur" provindo do Chile, em 1982; as linhagens 20 a 23 fizeram parte do "International Bread Wheat Spring Nursery", introduzido do CIMMYT em 1982.

18 ..... IAS-64/Aldan "S".

19 ..... IAS-58/Madeira "S" = IAC-191.

20 ..... Maya "S"/Moncho "S" = IAC-192.

21 ..... Junco "S".

22 ..... Trush "S" = IAC-193.

23 ..... Bluejay "S"/Jupateco = IAC-194.

Como controles, utilizaram-se os cultivares Alondra-S-46 e Anahuac, de porte semi-anão, resistentes à ferrugem-do-colmo, ciclo médio e sensiveis à toxicidade de $\mathrm{Al}^{3+}$, e cuja origem e genealogia é a seguinte:

'Alondra-S-46' - Selecionado pelo CIMMYT, a partir do cruzamento (D 6301/Nainari 60/Weique/Red Mace/3/ CIANO 67* 2/Chris), e introduzido pelo Centro Nacional de Pesquisa de Trigo, EMBRAPA, onde foi submetido a novo processo de seleção.

'Anahuac' - Introduzido do CIMMYT e provindo do cruzamento (II 12300//Lerma Rojo - 64/8156/3/Norteño-67).

Utilizou-se o delineamento estatístico de blocos ao acaso com três repetições por local. Cada ensaio foi constituído de 75 parcelas, cada uma formada de cinco linhas de $3 \mathrm{~m}$ de comprimento, espaçadas de $0,20 \mathrm{~m}$, com uma separação lateral de $0,60 \mathrm{~m}$ entre elas. A semeadura foi feita na base de 80 sementes viáveis por metro de sulco, equivalendo a 1.200 por parcela, com uma área útil de colheita de $3 \mathrm{~m}^{2}$.

No Centro Experimental de Campinas, efetuaram-se, em condição de irrigação por aspersão, três ensaios, em 1984, 1986 e 1987. Em condição de sequeiro, 
na Fazenda Santa Lúcia, ambas no município de Cruzália, e na Fazenda Ermilândia, município de Maracal, Vale do Paranapanema, realizaram-se dois ensaios, respectivamente em 1985 e 1986.

$\mathrm{Na}$ sua instalação, retiraram-se amostras compostas dos solos dos locais estudados, encontrando-se no quadro 1 os resultados da análise.

Coletaram-se os seguintes dados: ferrugem-da-folha (Puccinia recondita), mancha da folha (Helminthosporium sp. e/ou Septoria sp.), oídio (Erysiphe graminis sp. tritici), ciclo da emergência ao florescimento, acamamento, altura das plantas, comprimento da espiga, número de espiguetas, grãos por espiga e espigueta, peso de cem grãos e produção de grãos. A avaliação desses parâmetros foi efetuada conforme SCHRAMM et al. (1974); MEHTA (1978) e CAMARGO et al. (1990).

As características comprimento da espiga, número de espiguetas por espiga, número de grãos por espiga e por espigueta foram avaliadas somente nos ensalos de Campinas (1984) e Cruzália (1985) e o peso de cem grãos, apenas no ensaio de Cruzália (1985).

As características produção de grãos, altura das plantas, ciclo da emergência ao florescimento, comprimento da espiga, número de espiguetas por espiga, número de grãos por espiga e por espigueta e peso de cem grãos de cada experimento foram submetidas à análise da variância, utilizando-se o teste $F$ ao nivel de $5 \%$ para detectar efeitos significativos de genótipos e repetições. Analisaram-se as variâncias conjuntas para os experimentos de Campinas e do Vale do Paranapanema para produção de grãos, altura das plantas e ciclo da emergência ao florescimento, e para os de Campinas (1984) e Cruzália (1985) para comprimento da espiga, número de espiguetas por espiga e número de grãos por espiga e por espigueta, para detectar pelo teste $F$, ao nivel de $5 \%$, as significâncias dos efeltos de experimentos, genótipos e interação genótipos $x$ experimentos. A comparação das médias dos genótipos para produção de grãos nos experimentos ou nos grupos de experimentos foi feita pelo teste de Duncan ao nivel de $5 \%$ e para as demais características, pelo teste de Tukey ao nivel de $5 \%$.

As sementes dos genótipos estudados foram remetidas ao Centro Nacional de Pesquisa de Trigo da EMBRAPA, Passo Fundo (RS), para identificação, quanto à resistência em estádio de plântula, em condições de casa de vegetação, às duas misturas de raças de Puccinia graminis $\mathrm{f}$. sp. tritici, agente causal da ferrugem-docolmo (mistura 1: raças G15, G17, G18, G19, G20 e G21, e mistura 2: raças G22, G23 e G24) e às três misturas de raças de $P$. recondita, agente causal da ferrugem-da-folha (mistura 1: raças B27 e B29; mistura 2: raças B30, B31 e B32, e mistura 3: raças B25, B26, B27, B29, B30, B31, B32 e B33), de ocorrência comum no Brasil (BARCELLOS, 1986, e COELHO, 1986).

As plântulas das linhagens e dos cultivares foram testadas em condições de laboratório, para tolerância a 0, 2, 4, 6 e $10 \mathrm{mg} /$ litro de $\mathrm{Al}^{3+}$ em soluções nutritivas, conforme CAMARGO \& OLIVEIRA (1981); CAMARGO et al. (1987) e MOORE et al. 


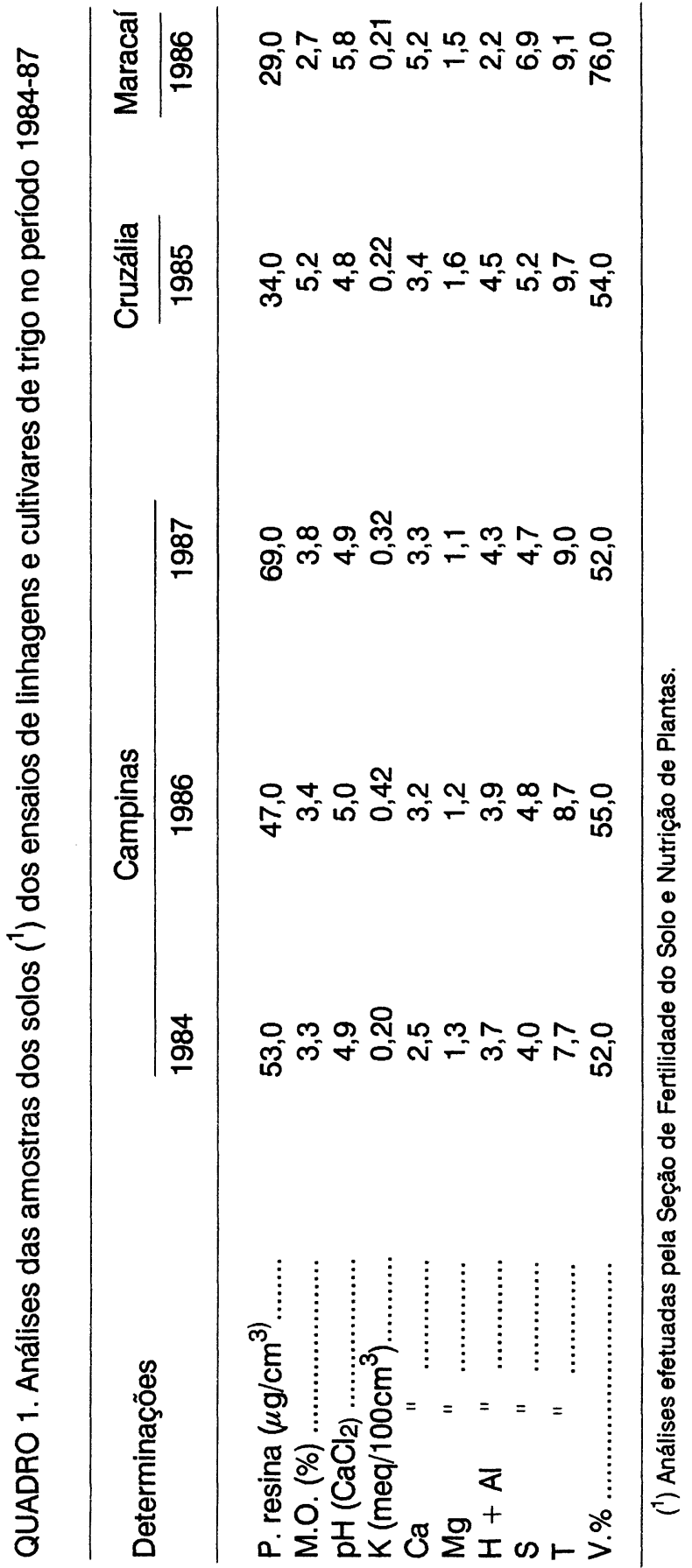


(1976). O delineamento estatístico empregado foi o de blocos ao acaso com parcelas subdivididas, sendo as parcelas compostas por seis concentrações de alumínio e as subparcelas, pelos genótipos de trigo. Realizaram-se duas repetições para cada solução de tratamento. $\mathrm{Na}$ análise dos dados, considerou-se a média de comprimento da raiz primária central das dez plântulas de cada genótipo, em 72 horas de crescimento nas soluções nutritivas completas sem alumínio, que se seguiu a 48 horas de crescimento nas soluções de tratamento contendo seis diferentes concentrações de alumínio.

\section{RESULTADOS E DISCUSSÃO}

Os quadrados médios das análises da variância individual das produções de grãos dos genótipos (linhagens e cultivares) de trigo estudados nos ensaios instalados em Campinas em 1984, 1986 e 1987, em Cruzália (1985) e em Maracal (1986) mostraram efeitos significativos para genótipos nos cinco experimentos e para repetições somente nos ensaios de Campinas (1986) e Cruzália (1985).

Os quadrados médios da análise da variância conjunta das produções médias dos genótipos dos ensaios em condição de irrigação por aspersão, em Campinas, mostraram efeitos altamente significativos para experimentos e interação genótipos $x$ experimentos, porém os efeitos de genótipos foram não significativos.

Através do teste de Duncan aplicado ao nível de $5 \%$ para a comparação das médias de produção de grãos dos tratamentos dos ensaios com irrigação por aspersão - Quadro 2 - verificou-se, no de Campinas, em 1984, que a linhagem IAC-190 mostrou a maior produção de grãos $(2.055 \mathrm{~kg} / \mathrm{ha})$, diferindo, porém, somente das linhagens 7, 8, IAC-185, 14 e IAC-192 e do cultivar Alondra-S-46; no ensaio de 1986, a linhagem IAC-243 foi a mais produtiva, com $3.409 \mathrm{~kg} / \mathrm{ha}$, somente não diferindo, porém, das linhagens 11, IAC-190, 17 e IAC-194; no de 1987, a linhagem IAC-187 exibiu a maior produção de grãos $(2.847 \mathrm{~kg} / \mathrm{ha})$, diferindo das linhagens 2, IAC-182, IAC-183, IAC-243, IAC-186, IAC-189, IAC-192 e IAC-194 e de ambos os cultivares. Considerando-se a média dos três experimentos de Campinas, observou-se que as linhagens IAC-243, IAC-187, IAC-188 e IAC-190 produziram $2.313,2.366,2.370$ e $2.471 \mathrm{~kg} / \mathrm{ha}$ respectivamente, enquanto $O$ 'Alondra-S-46' e o 'Anahuac' produziram 1.553 e $1.854 \mathrm{~kg} / \mathrm{ha}$ respectivamente; contudo, não foram calculadas as diferenças mínimas significativas entre os tratamentos, pelo teste de Duncan, por não terem sido observados efeitos significativos para genótipos (teste F) na análise da variância conjunta, devido a uma elevada e significativa interação genótipos $\mathrm{x}$ experimentos.

Os quadrados médios da análise da variância conjunta das produções médias de grãos dos genótipos estudados nos ensaios em condição de sequeiro, no Vale do Paranapanema, em Cruzália (1985) e Maracaí (1986), mostraram efeitos significativos para experimentos, genótipos e interação genótipos $\mathrm{x}$ experimentos. 


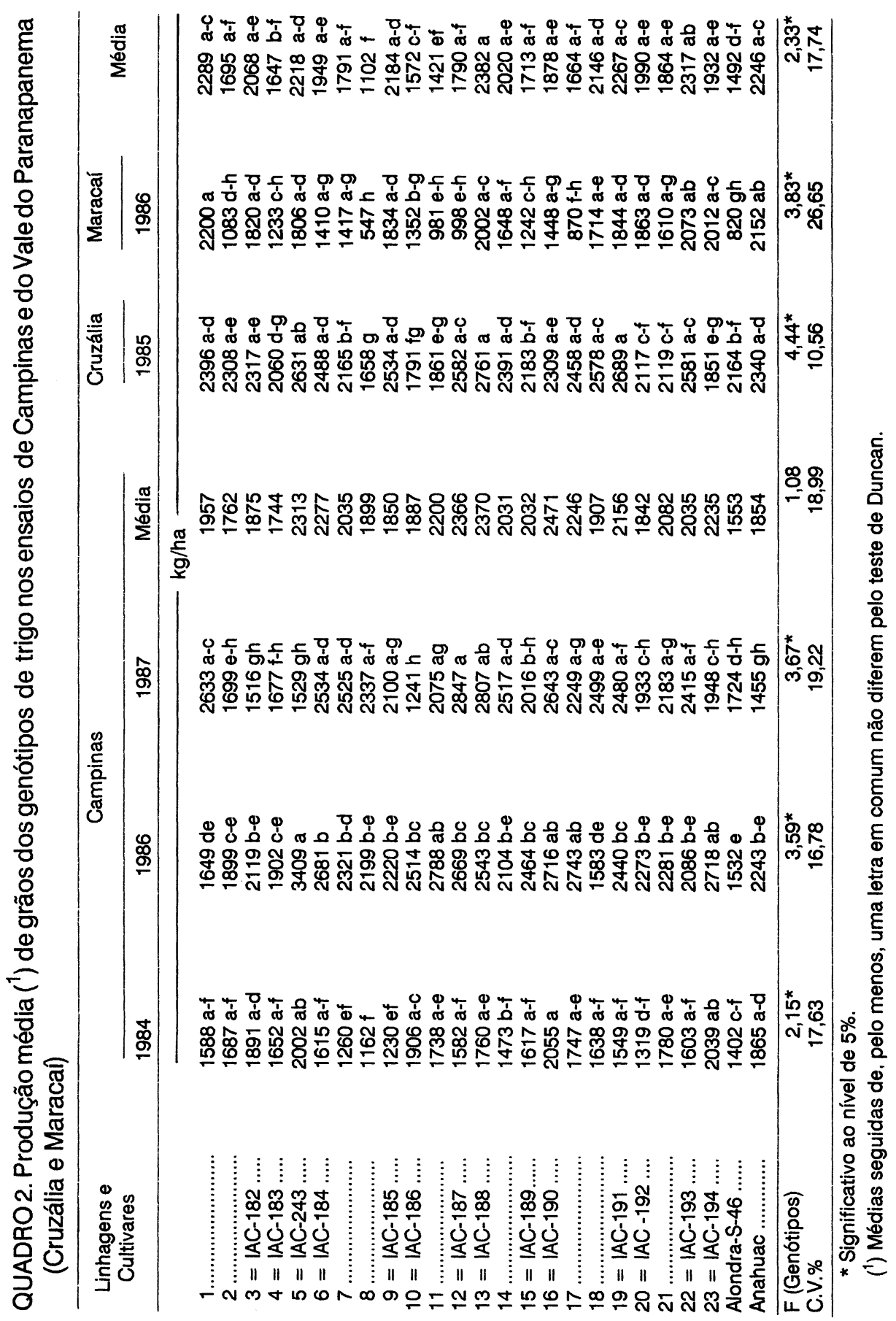


As produções médias de grãos dos genótipos dos ensaios do Vale do Paranapanema, em 1985 e 1986, encontram-se no quadro 2. No de Cruzália, em 1985, as linhagens IAC-188, IAC-191 e IAC-243 mostraram as maiores produções de grãos $(2.761,2.689$ e $2.631 \mathrm{~kg} / \mathrm{ha}$ respectivamente), não diferindo entre si. As duas primeiras somente diferiram ao nível de $5 \%$ das linhagens IAC-183, 7, 8, IAC-186, 11, IAC-189, IAC-192, 21 e IAC-194 e do cultivar Alondra-S-46; em 1986, a linhagem 1 foi a mais produtiva $(2.200 \mathrm{~kg} / \mathrm{ha})$, somente diferindo, porém, das linhagens 2, IAC-183, 8, IAC-186, 11, IAC-187, IAC-189 e 17 e do cultivar AlondraS-46. Considerando a média dos dois ensaios no Vale do Paranapanema (Quadro 1), as linhagens IAC-188 e IAC-193 apresentaram maior produção de grãos, respectivamente 2.382 e $2.317 \mathrm{~kg} / \mathrm{ha}$, mas só diferiram das linhagens 8 e IAC-186 e 11 e do 'Alondra-S-46', as menos produtivas. A IAC-188 também diferiu da IAC-183.

A linhagem IAC-188 esteve entre as mais produtivas na média dos ensaios com irrigação por aspersão, em Campinas, e em condição de sequeiro, no Vale do Paranapanema, exibindo, portanto, grande estabilidade de produção e ampla adaptação às diferentes condições de ambiente.

Os graus médios de infecção de ferrugem-da-folha, oídio e mancha da folha, nos genótipos de cada experimento instalado em Campinas e no Vale do Paranapanema encontram-se no quadro 3.

Em relação à ferrugem-da-folha, destacaram-se, quanto à resistência em planta adulta, as linhagens 11, 17, IAC-192, 21 e IAC-193, que se apresentaram imunes, e as linhagens 14, 18, IAC-191 e IAC-194 e os cultivares Alondra-S-46 e Anahuac, com reações variando de 0 a $10 \mathrm{~S}$. Nas mesmas condições, as linhagens 1, 2, IAC-182, IAC-185, IAC-243, IAC-184, 7, 8, IAC-185, IAC-186 e IAC-188 foram altamente suscetiveis à ferrugem-da-folha, apresentando, em pelo menos um dos experimentos, um grau de infecção igual ou superior a 60S. As linhagens IAC-243, IAC-187, IAC-188 e IAC-190, que estiveram entre as mais produtivas nos ensaios de Campinas, mostraram-se sensíveis à ferrugem-da-folha, havendo necessidade, portanto, de incorporar, nesses genótipos, resistência genética ao agente causal da moléstia.

Nos experimentos considerados, não houve ocorrência de condições naturais favoráveis para infecção do agente causal da ferrugem-do-colmo.

As linhagens 8, IAC-185, IAC-186, IAC-187, IAC-189, 17, IAC-193 e IAC-194 apresentaram-se como moderadamente resistentes ao oídio em estádio de planta adulta, com grau máximo de infecção de $20 \mathrm{em}$, pelo menos, um dos experimentos. As linhagens 1 e IAC-184 e o cultivar Alondra-S-46 foram altamente suscetiveis.

Em relação às manchas foliares, sobressaíram, como moderadamente resistente, as linhagens 11, IAC-187 e 17. As linhagens IAC-243, IAC-192 e IAC-193 e o cultivar Anahuac foram os mais suscetiveis entre os genótipos avaliados em estádio de planta adulta, em condições naturais de infecção. 


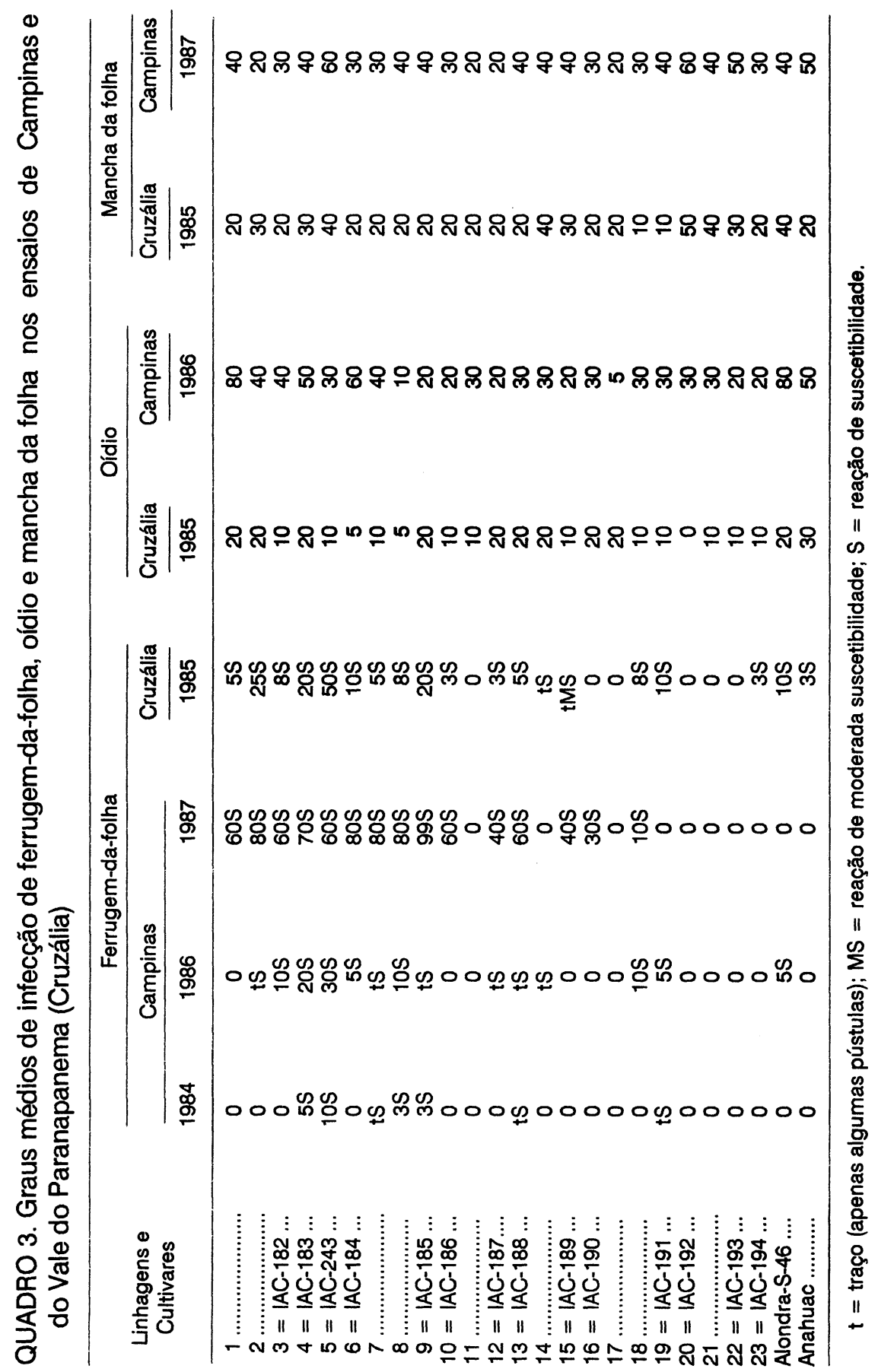




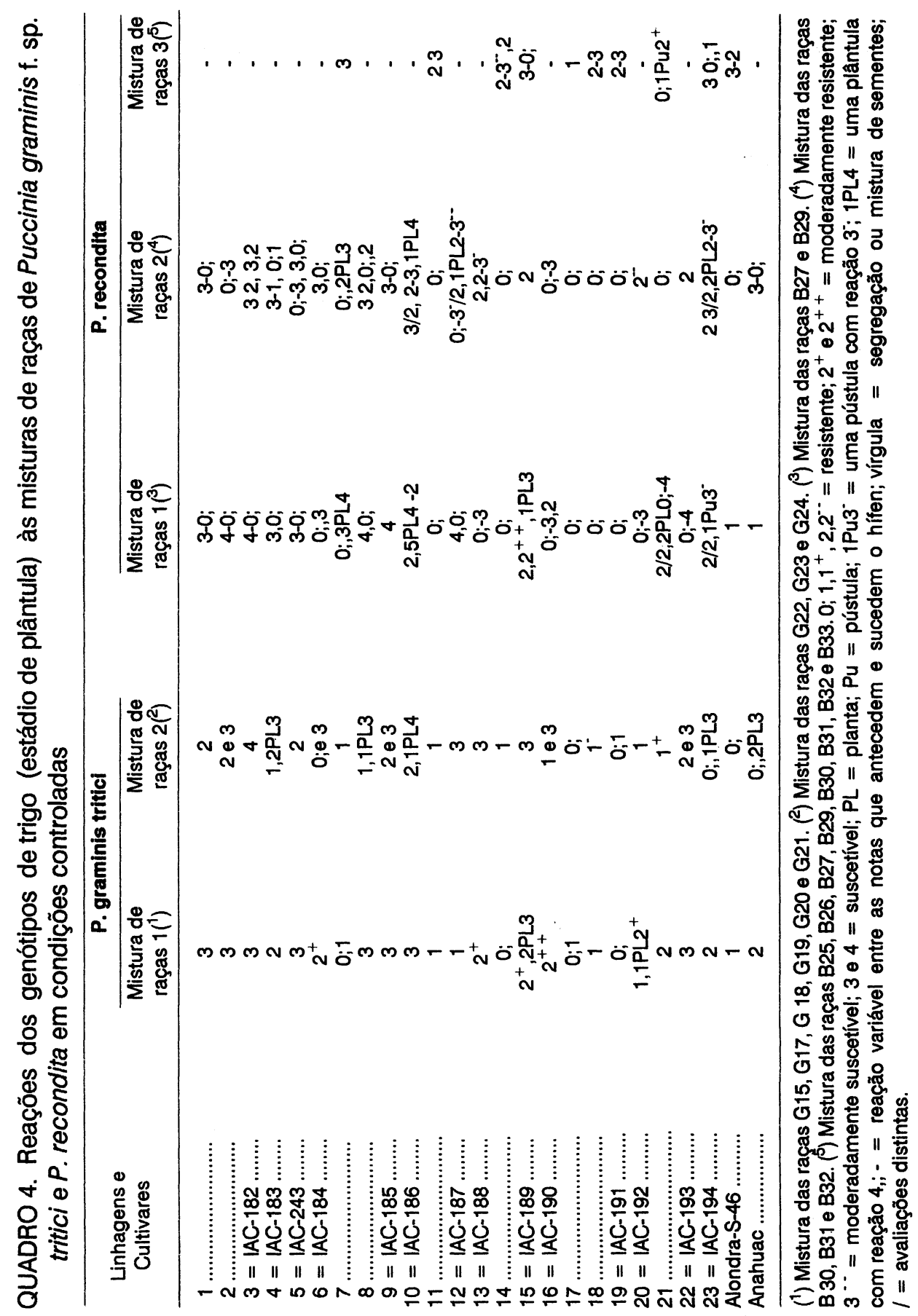


As reações das linhagens e dos cultivares (estádio de plântula) a Puccinia graminis $f$. sp. tritici e $P$. recondita, em casa de vegetação, encontram-se no quadro 4. As linhagens 7, 11, 14, 17, 18, IAC-191 e 21 e o cultivar Alondra-S-46 foram resistentes às duas misturas de raças prevalecentes do agente causal da ferrugem-do-colmo, em condições de casa de vegetação, constituindo fontes genéticas de valor ao programa de melhoramento do trigo no Instituto Agronômico. A 17 mostrou-se resistente às três misturas de raças prevalecentes do agente causal da ferrugem-da-folha, em estádio de plântula, e exibiu imunidade ao patógeno em condições de campo (planta adulta), constituindo, portanto, germoplasma de valor ao programa de melhoramento genético. As linhagens 11, 18 e IAC-191 e o cultivar Alondra-S-46 foram resistentes às misturas de raças $1 \mathrm{e} 2$, porém algumas plântulas segregaram entre as reações 2 e 3 , quando testadas para a mistura de raças 3 , da ferrugem-da-folha. A linhagem 11 foi imune ao agente causal da ferrugem-da-folha em condição de campo e as linhagens 18 e IAC-191 mostraram um grau máximo de infecção, em condições naturais, em estádio de planta adulta igual a $10 \mathrm{~S}$ (Quadro 3). Isso sugere que as raças para as quais essas linhagens são suscetíveis não foram prevalecentes nas condições estudadas.

Os quadrados médios da análise da variância conjunta para altura da planta dos genótipos, no período 1984-87, mostraram efeitos significativos para genótipos e experimentos e não significativos para a interação genótipos $x$ experimentos.

A altura média das plantas dos genótipos de trigo estudados em cada um dos experimentos encontra-se no quadro 5: as linhagens 2, IAC-182, IAC-184, 7, 8, IAC-185, 11, IAC-189, IAC-190 e IAC-191 mostraram as plantas mais altas, diferindo significativamente das linhagens IAC-243, IAC-192, 21, IAC-193 e dos cultivares semi-anões Alondra-S-46 e Anahuac, com as plantas mais baixas. Esses germoplasmas mais as linhagens IAC-185, IAC-187, IAC-188, 17 e IAC-194, apresentaram menor porcentagem de plantas acamadas, estando, portanto, entre aqueles com potencial de cultivo em condição de irrigação por aspersão. As linhagens IAC-182, 7, 18 e IAC-191 apresentaram-se com uma porcentagem média de plantas acamadas variando de 50 a 80 , que foi associada a um porte de planta de médio para alto - Quadro 6.

Os quadrados médios da análise da variância conjunta para ciclo em dias da emergência ao florescimento dos genótipos de Campinas e do Vale do Paranapanema mostraram efeitos significativos para genótipos, experimentos e interação genótipos $\mathrm{x}$ experimentos.

Os ciclos médios, em dias, da emergência ao florescimento dos genótipos estudados em cada um dos ensaios encontram-se no quadro 7: as linhagens 2, IAC-182, IAC-183, IAC-243, IAC-186, 11, IAC-187, IAC-189, IAC-190, 17 e IAC-194 foram as mais tardias para florescer, não diferindo significativamente dos dois cultivares controles; por outro lado, as linhagens 1, 18, IAC-191, IAC-192 e IAC-193 foram as mais precoces, diferindo dos cultivares Alondra-S-46 e Anahuac, sendo, portanto, fontes genéticas dessa característica de interesse ao programa de melhoramento. 


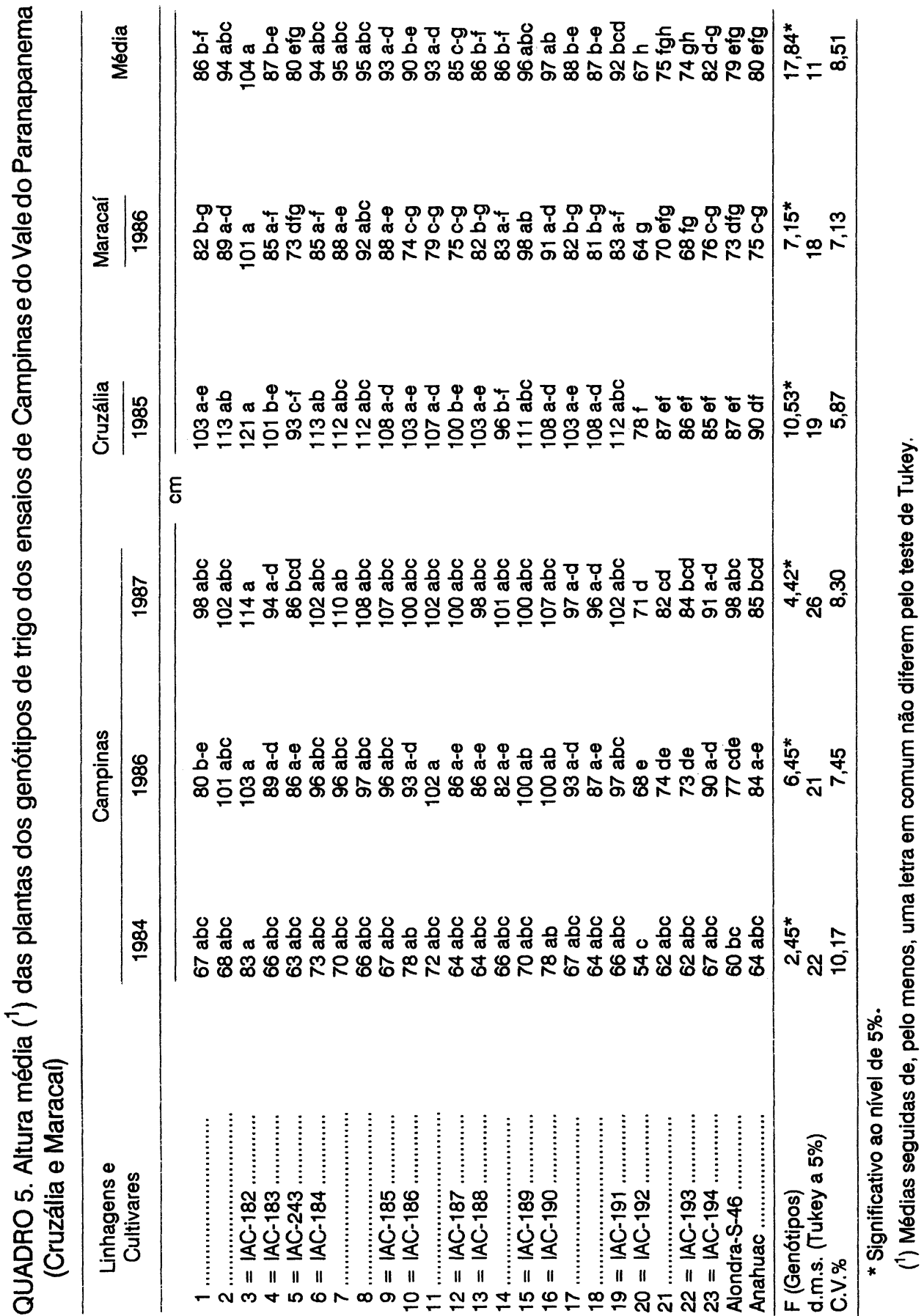




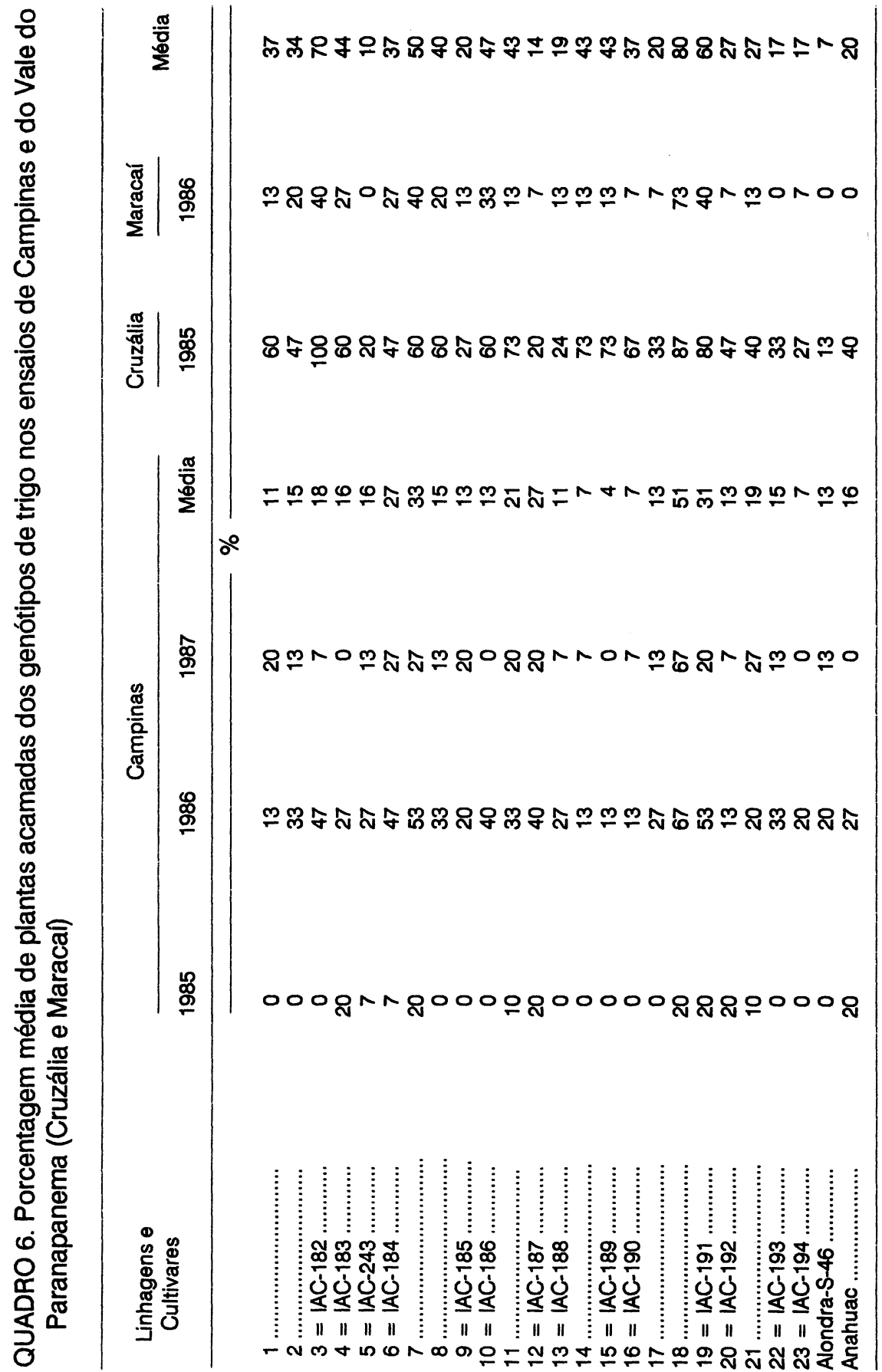




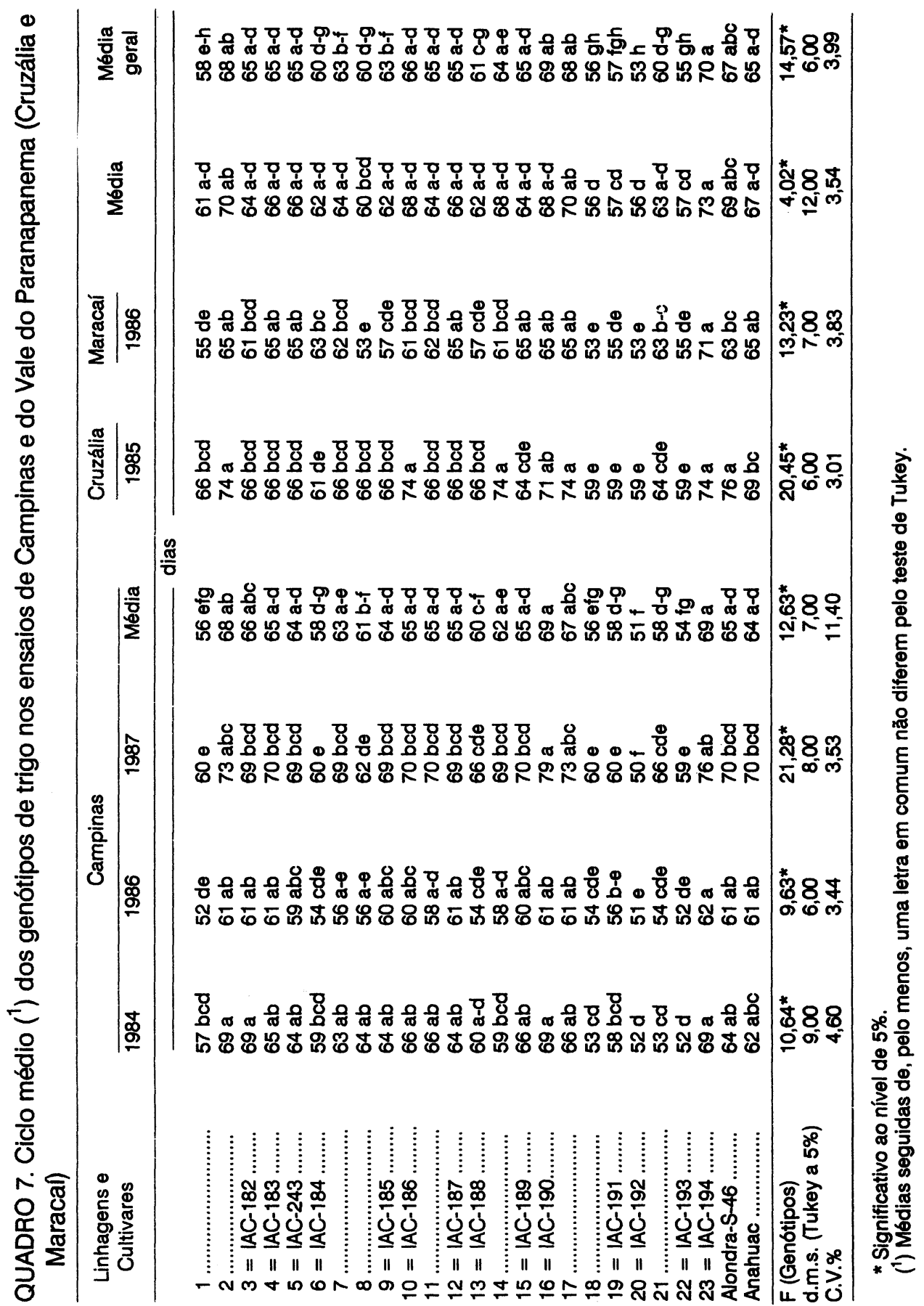


Os quadrados médios das análises da variância conjunta para comprimento da espiga, número de espiguetas por espiga e númèro de grãos por espiga e por espigueta dos genótipos dos ensaios de Campinas e Cruzália mostraram, para todas as características consideradas, efeitos significativos para genótipos (com exceção do número de grãos por espigueta) e experimentos, e efeitos não significativos para a interação genótipos $x$ experimentos.

O cultivar Alondra-S-46 apresentou as espigas mais compridas, diferindo, na média dos dois experimentos, porém, somente das linhagens 8, IAC-185, 11, 17, 18 e IAC-191 - Quadro 8. Esse resultado também foi observado por CAMARGO et al. (1987), sendo, portanto, já utilizado o 'Alondra-S-46' como fonte genética para aumentar o comprimento das espigas no programa de melhoramento do Instituto Agronômico.

Em relação ao número de espiguetas por espiga, a linhagem IAC-182 apresentou o maior valor, utilizando a média dos dois ensaios considerados, diferindo significativamente, ao nivel de $5 \%$, pelo teste de Tukey, dos demais genótipos - Quadro 8.

Em virtude de não serem observadas diferenças significativas para as características número de grãos por espiga e por espigueta entre os genótipos, levando em consideração a média dos dois experimentos, decidiu-se compará-los em relação a essas características, utilizando os dados do ensaio de Campinas (1984). O cultivar Anahuac apresentou o maior número de grãos por espiga, diferindo somente, porém, das linhagens IAC-243, IAC-184, 7, 8, IAC-185, IAC-188, 14 e IAC-191; apresentou também o maior número de grãos por espigueta, diferindo das linhagens 1, IAC-182, IAC-243, IAC-184, 7, 8, IAC-187, IAC-188, 14, 17, 18 e IAC-191. O 'Anahuac', recomendado para plantio nas diferentes regiões tritícolas paulistas, em solos corrigidos, mostrou ser uma fonte genética de valor visando ao aumento do número de grãos por espiga e por espigueta, características essas necessárias de serem melhoradas na maioria dos cultivares atualmente recomendados para o Estado de São Paulo.

As linhagens IAC-188 e 17 revelaram os grãos mais pesados, considerando o experimento de Cruzália (1985), mas não diferindo das linhagens 1, IAC-182, IAC-243, IAC-184, 7, 8, IAC-185, 11, IAC-187, 14 e IAC-189 e do 'Alondra-S-46' (Quadro 8).

O comprimento médio das raízes das linhagens e dos dois cultivares, medido após 72 horas de crescimento nas soluções nutritivas completas, que se seguiu a 48 horas de crescimento nas soluções de tratamento contendo seis concentrações de alumínio, encontra-se no quadro 9 . Considerando $2 \mathrm{mg} / \mathrm{litro}$ de $\mathrm{Al}^{3+}$, pode-se verificar que as linhagens 1, IAC-183, IAC-185, 11, 14, IAC-189, IAC-190, 17, IAC-192, 21 e IAC-194 e o 'Anahuac' foram sensíveis a essa concentração e os demais genótipos, tolerantes. 


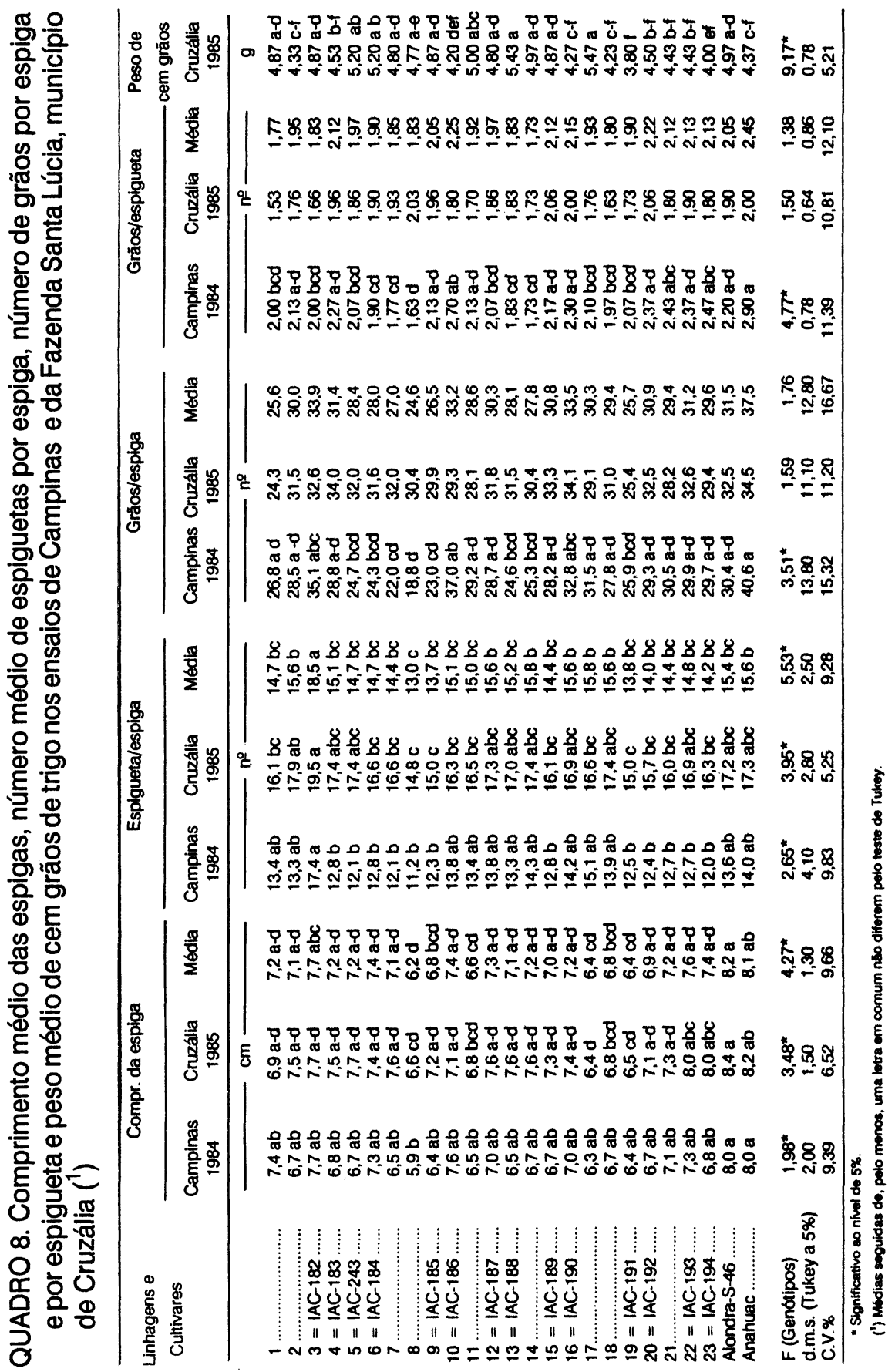




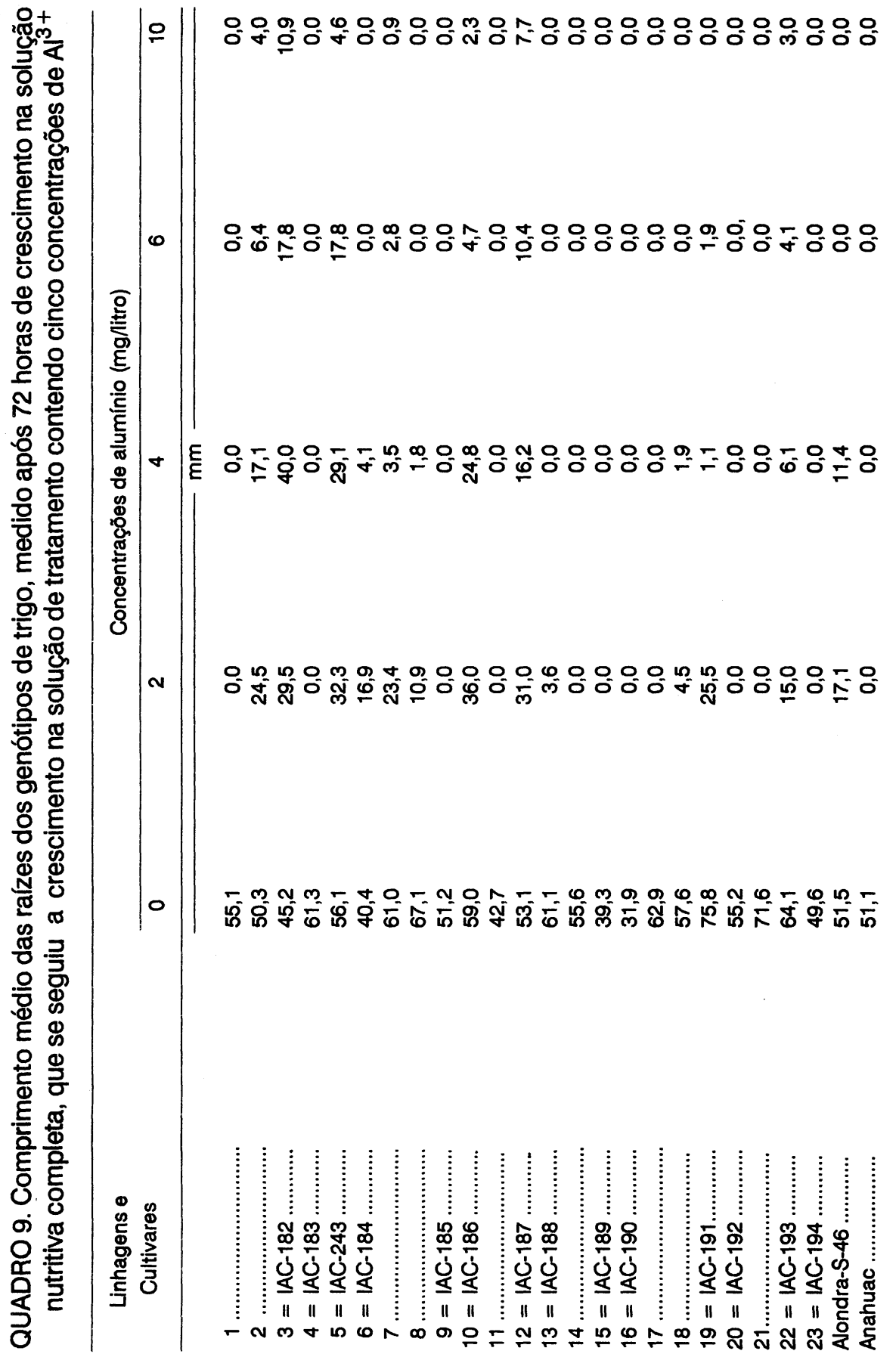


A linhagem IAC-188 foi tolerante a $2 \mathrm{mg} /$ itro de $\mathrm{Al}^{3+}$ na solução tratamento, porém mostrou sensibilidade a $4 \mathrm{mg} /$ /itro, sendo, portanto, considerada moderadamente sensível.

As linhagens IAC-184, 8 e 18 e o 'Alondra-S-46' foram tolerantes a 4mg/itro de $\mathrm{Al}^{3+}$, porém demonstraram sensibilidade a $6 \mathrm{mg} /$ litro de $\mathrm{Al}^{3+}$ nas soluções de tratamento, sendo considerados moderadamente tolerantes.

A linhagem IAC-191 foi sensível a $10 \mathrm{mg} /$ litro de $\mathrm{Al}^{3+}$, porém tolerante a $6 \mathrm{mg} /$ litro de $\mathrm{Al}^{3+}$, sendo, portanto, considerada tolerante.

As linhagens 2, IAC-182, IAC-243, 7, IAC-186, IAC-187 e IAC-193 exibiram crescimento das raízes mesmo quando se adicionaram $10 \mathrm{mg} / \mathrm{litro}$ de $\mathrm{Al}^{3+}$, sendo consideradas as mais tolerantes à toxicidade de $\mathrm{Al}^{3+}$

As linhagens IAC-243 e IAC-187, muito tolerantes, a IAC-188, moderadamente sensivel, e a $\mid A C-190$, sensivel à toxicidade de $\mathrm{Al}^{3+}$, foram as mais produtivas em Campinas. Considerando que os solos de Campinas apresentaram porcentagem de saturação por bases variando entre 52 e 55 (Quadro 1) e que, nessas condições, o efeito nocivo do $\mathrm{Al}^{3+}$ às raízes das plantas sensíveis seria bastante minimizado, os resultados discordam dos obtidos por PRIOLI (1987), que mostrou, em milho, uma associação entre baixa produtividade e tolerância ao $\mathrm{Al}^{3+}$ quando os híbridos foram cultivados em solos de baixa acidez.

As linhagens IAC-188, moderadamente sensível, e IAC-193, muito tolerante à toxicidade de $\mathrm{Al}^{3+}$, foram as mais produtivas no Vale do Paranapanema (Quadro 2) em solos com porcentagem de saturação por bases variando entre 54 e 76 (Quadro 1). Os resultados obtidos concordam com os de BRIGGS et al. (1989), que encontraram cultivares de trigo tolerantes e sensiveis ao $\mathrm{Al}^{3+}$ entre os mais produtivos quando cultivados em solos de alta fertilidade e pH 6,0.

\section{CONCLUSÓES}

1. As linhagens IAC-243, IAC-187 e IAC-188, de porte baixo, resistentes ao acamamento, de ciclo médio, e a IAC-190, de porte médio, destacaram-se quanto à produção de grãos, em condições de irrigação. Em condição de sequeiro, sobressaíram pela boa produtividade IAC-188 e IAC-193.

2. As linhagens $7,11,14,17,18, I A C-191$ e 21 e o cultivar Alondra-S-46 apresentaram-se como fontes genéticas de valor pela resistência à ferrugem-docolmo, e a 17, também pela resistência e/ou imunidade à ferrugem-da-folha.

3. O cultivar Alondra-S-46 mostrou ser fonte genética do caráter espiga comprida; a linhagem IAC-182, de maior número de espiguetas por espiga; 0 cultivar Anahuac, de maior número de grãos por espiga e por espigueta e as linhagens IAC-188 e 17, de grãos mais pesados. 
4. As linhagens 2, IAC-182, IAC-243, 7, IAC-186, IAC-187 e IAC-193 foram mais tolerantes à toxicidade de $\mathrm{Al}^{3+}$.

\section{AGRADECIMENTOS}

Os autores agradecem ao Centro Nacional de Pesquisa de Trigo (EMBRAPA) os testes de resistência à ferrugem-do-colmo e da-folha, em casa de vegetação.

\section{REFERÊNCIAS BIBLIOGRÁFICAS}

BARCELLOS, A.L. Ferrugem da folha do trigo no Brasil em 1984 e 1985: ocorrência e virulência. In: REUNIÃO NACIONAL DE PESQUISA DE TRIGO, 14., Londrina, 1986. Resultados de pesquisa. Passo Fundo, EMBRAPA-CNPT, 1986. p.117-131.

BRIGGS, K.G.; TAYLOR, G.J.; STURGES, I. \& HODDINOTT, J. Differential aluminum tolerance of high-yielding, early maturing Canadian wheat cultivars and germoplasm. Canadian Journal of Plant Science, Ottawa, 69(1):61-69, 1989.

CAMARGO, C.E. de O. Estudos de variedades de trigo para o Estado de São Paulo. Piracicaba, ESALQ, 1972. 102p. Tese (Doutorado).

; ALCOVER, M. \& ISSA, E. Comportamento de cultivares de trigo em condiçöes de sequeiro no Estado de São Paulo. Bragantia, Campinas, 33:43-53, 1974.

\& FELÍCIO, J.C. Melhoramento genético do trigo no Instituto Agronômico. O Agronómico, Campinas, 38(3):213-228, 1986.

- ; ; FERREIRA FILHO, A.W.P.; FREITAS, J.G. de; BARROS, B. de C.; CASTRO, J.L. de; SABINO, J.C. \& KANTHACK, R.A.D. Melhoramento do trigo: $X X 11$. . Avaliação de linhagens na região do vale do Paranapanema, em Capão Bonito e em Tietê, em 1984-88. Bragantla, Campinas, 49(1):43-67, 1990.

—; - FREITAS, J.G. de; FERREIRA FILHO, A.W.P.; BARROS, B. de C.; PEITINELLI JÚNIOR, A.; SANTOS, R.R. dos; KANTHACK, R.A.D \& ROCHA JÚNIOR, L.S. Melhoramento do trigo: XVII. Comportamento de linhagens de origem mexicana no Estado de São Paulo. Bragantia, Campinas, 47(1):25-41, 1988.

\& ROCHA JÚNIOR, L.S. Trigo: tolerância ao alumínio em solução nutritiva. Bragantia, Campinas, 46(2):183-190, 1987.

\& OLIVEIRA, O.F. de. Tolerância de cultivares de trigo a diferentes níveis de alumínio em solução nutritiva e no solo. Bragantia, Campinas, 40:21-31, 1981.

COELHO, E.T. Avaliação de resistência à ferrugem do colmo das cultivares dos ensaios regionais de rendimento de variedades de trigo do Cone Sul (ERCOS). In: REUNIÃO NACIONAL DE PESQUISA DE TRIGO, 14., Londrina, 1986. Resultados de pesquisa. Passo Fundo, EMBRAPA-CNPT, 1986. p.101-110.

FELÍCIO, J.C.; CAMARGO, C.E. de O. \& BARROS, B. de C. Estudo comparativo de cultivares de trigo em latossolo roxo no Estado de São Paulo em 1974. Bragantia, Campinas, 35:147-154, 1976. 
FERREIRA FILHO, A.W.P.; CAMARGO, C.E. de O.; FELICIO, J.C. \& FREITAS, J. G. de. Estabilidade de rendimento de grãos de trigo na região do Vale do Paranapanema, SP. Bragantia, Campinas, 49(1):83-92, 1990.

MEHTA, Y.R. Doenças do trigo e seu controle. Săo Paulo, Agronômica Ceres, 1978. 190p. (Ceres, 20)

MOORE, D.P.; KRONSTAD, W.E. \& METZGER, R.J. Screening wheat for aluminum tolerance. In: WORKSHOP ON PLANT ADAPTATION TOMINERAL STRESS IN PROBLEM SOILS, Beltsville, 1976. Proceedings. Ithaca, Cornell University, 1976. p.287-295.

PRIOLI, A.J. Análise genética da tolerância à toxidez do alumínio em milho (Zea mays L.). Campinas, UNICAMP - Instituto de Biologia, 1987. 182p. Tese (Doutorado).

SCHRAMM, W.; FULCO, W.S.; SOARES, M.H.G. \& ALMEIDA, A.M.P. Resistência de cultivares de trigo em experimentação ou cultivo no Rio Grande do Sul, às principais doenças fúngicas. Agronomia Sulriograndense, Porto Alegre, 10(1):31-52, 1974. 